\title{
Spinal cord atrophy in spinocerebellar ataxia type 1
}

Atrofia da medula espinhal na ataxia espinocerebelar do tipo 1

José Luiz Pedroso, Orlando G. P. Barsottini

A 50-year-old man presented with 9-years history of progressive ataxia. His father had undiagnosed ataxia. Examination showed ataxia and pyramidal signs. Brain MRI: olivopontocerebellar atrophy; spine MRI: global spinal cord atrophy (Figure). Genetic test confirmed spinocerebellar ataxia type-1 (SCA1).

SCA1 is characterized by cerebellar ataxia with variable degrees of ophthalmoplegia, pyramidal signs, and peripheral neuropathy ${ }^{1}$. Spinal cord atrophy was described in other SCA subtypes, but not in $\mathrm{SCAl}^{2}$. Prominent pyramidal signs and spinal cord atrophy in SCA1 may be explained by long tracts involvement, as in hereditary spastic paraplegia ${ }^{3}$. Spinal cord atrophy must be considered in neuroimaging features related to SCA1.
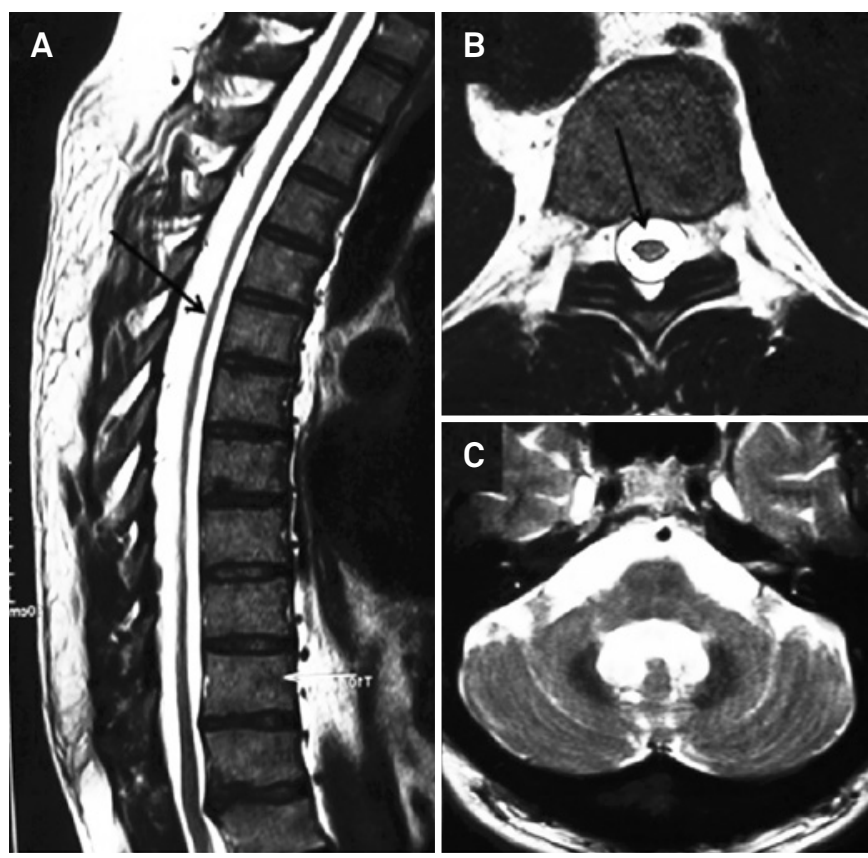

Figure. A. Sagittal T2-weighted spine MRI demonstrates global spinal cord atrophy; B. Axial T2-weighted spine MRI shows a marked reduced transverse diameter of the thoracic spinal cord; C. Axial T2-weighted brain MRI discloses moderate olivopontocerebellar atrophy.

\footnotetext{
1. Matilla-Dueñas A, Goold R, Giunti P. Clinical, genetic, molecular, and pathophysiological insights into spinocerebellar ataxia type 1. Cerebellum 2008;7:106-114.

2. Lukas C, Hahn HK, Bellenberg B, et al. Spinal cord atrophy in spinocerebellar ataxia type 3 and 6 : impact on clinical disability. J Neurol 2008;255:1244-1249.
}

3.

Gilman S, Sima AA, Junck L, et al. Spinocerebellar ataxia type 1 with multiple system degeneration and glial cytoplasmic inclusions. Ann Neurol 1996;39:241-255.

Departamento de Neurologia e Neurocirurgia, Setor de Neurologia Geral e Ataxias, Universidade Federal de São Paulo, Sao Paulo SP, Brazil. Correspondence: José Luiz Pedroso; Rua Botucatu 740;04023-900 São Paulo SP - Brasil; E-mail: jlpedroso.neuro@gmail.com Conflict of interests: There is no conflict of interest to declare.

Received 20 February 2013; Received in final form 18 June 2013; Accepted 25 June 2013. 